\title{
INDICADORES BIBLIOMÉTRICOS DOS ARTIGOS SOBRE “COVID-19" NA BASE SCOPUS
}

\author{
BIBLIOMETRIC INDICATORS OF ARTICLES ON “COVID-19” IN THE SCOPUS BASE
}

\begin{abstract}
Ana Gabriela Poppe Gicovate ${ }^{1}$, Arthur Leal Prestes Marins', Carlos Gicovate Neto² e Eduardo Shimoda ${ }^{3}$.
${ }^{1}$ Discentes da Faculdade de Medicina de Campos, Campos dos Goytacazes, RJ, Brasil. ${ }^{2}$ Docente da Faculdade de Medicina de Campos, Campos dos Goytacazes, RJ, Brasil. ${ }^{3}$ Doutorado em Ciência Animal (UENF). Professor da Universidade Cândido Mendes (UCAM), Campos dos Goytacazes, RJ, Brasil.
\end{abstract}

Faculdade de Medicina de Campos (FMC). Avenida Alberto Torres, 217 - Centro - Campos dos Goytacazes /RJ. Tel: (22) 2101-2929

Ana Gabriela Poppe Gicovate. Avenida Alberto Lamego, 555. Tel: (22) 988237972. anaggicovate@gmail.com

\section{RESUMO}

A COVID-19 é uma doença viral recém descoberta, causada pelo SARS-CoV-2, que se tornou uma pandemia com 25 milhões de infectados e 848 mil óbitos. Este trabalho objetiva avaliar a produção científica acerca deste tema, através do levantamento de dados na base Scopus de todos os artigos publicados em periódicos que apresentam o termo "COVID-19" em título, resumo ou palavraschaves. Os resultados obtidos foram: países com mais publicações sobre COVID-19: Estados Unidos, China e Itália. O Brasil ficou em 11‥ Instituições com mais publicações: HUST, Tongji Medical College e Harvard Medical School. No Brasil: USP (São Paulo), FIOCRUZ e UFMG. Os autores com mais publicações no mundo são Mahase, E., laccobucci, G. e Rimmer, A. No Brasil, Angeletti, S., Benvenuto, D., Ciccozzi, M. e Giovanetti, M. Os periódicos que mais publicaram sobre o tema: British Medical Journal, Clinical Research, International Journal Of Environmental Research And Public Health e Journal Of Medical Virology. No Brasil: Cadernos de Saúde Pública, Clinics São Paulo Brazil e Ciência E Saúde Coletiva. Principias áreas de vinculação dos artigos: Medicina, Ciências Sociais e Bioquímica e Genética. Idiomas das publicações: Inglês, Chinês e Espanhol. No Brasil, o português foi o segundo idioma mais utilizado. Concluiu-se que os países com maior poder econômico apresentaram mais publicações sobre todos os temas e sobre COVID-19, porém, nesse caso, com maior participação daqueles países que foram mais impactados pela doença, a exemplo de Brasil e Itália, que sobem no ranque de países que mais publicaram sobre a doença.

Palavras-Chave: COVID-19, SARS-CoV-2, Coronavírus, Bibliometria, Análise Bibliométrica.

\section{ABSTRACT}

The COVID-19 is a newly discovered viral disease, caused by SARS-CoV-2, which has become a pandemic with 25 million people infected and 848 thousand deaths. This work aims to evaluate the scientific production on this theme by collecting data through the Scopus database from all articles published in journals that present the term "COVID-19" in the title, abstract or keywords. The results obtained were: countries with the most publications on COVID-19: United States, China and Italy. Brazil ranked 11th. Institutions with the most publications: HUST, Tongji Medical College and Harvard Medical School, in Brazil: USP (São Paulo), FIOCRUZ and UFMG. The authors with the most publications in the world are Mahase, E., laccobucci, G. and Rimmer, A. In Brazil, Angeletti, S., Benvenuto, D., Ciccozzi, M. and Giovanetti, M. The journals that most published on the theme: British Medical Journal, Clinical Research, International Journal of Environmental Research And Public Health and Journal Of Medical Virology. In Brazil: Cadernos De Saúde Pública, Clinics São Paulo BrazilandCiência E Saúde Coletiva. Main linking areas of the articles: Medicine, Social Sciences and Biochemistry and Genetics. Publication languages: English, Chinese and Spanish. In Brazil, Portuguese was the second most used language. It was concluded that the countries with greater economic power presented more publications on all topics and on COVID-19, however, in this case with greater participation of those that were most impacted by the disease, such as Brazil and Italy, which rise in the ranking of countries that most published about the disease.

Keywords: COVID-19, SARS-CoV-2, coronavirus, bibliometrics, bibliometric analysis. 


\section{INTRODUÇÃO}

A doença infecciosa do coronavírus pandêmico COVID-19 é uma doença viral descoberta em dezembro de 2019 na cidade de Wuhan, na China (CHAHROUR et al., 2020). Esta virose se disseminou por todos os continentes, tornando-se um grave problema para a saúde mundial (HOFFMANN et al., 2020).

A COVID-19 tem como agente etiológico um vírus de RNA de fita simples da família Coronaviridae, também conhecido como Coronavírus 2 da Síndrome Respiratória Aguda Grave (SARS-CoV-2), e apresenta uma alta transmissibilidade via aerossóis e gotículas, podendo gerar desde casos leves até casos mais grave e desfechos fatais (MELO et al., 2020). Indivíduos infectados pelo SARS-CoV-2 normalmente apresentam infecção do trato respiratório inferior e os principais sintomas conhecidos são febre ou sensação de febre, dispneia, tosse, fadiga, diarreia, cefaleia e hemoptise (ADHIKARI et al., 2020). O aspecto tomográfico dos pulmões, em vidro fosco, é característica marcante da doença (YANG et al., 2020).

Segundo a Organização Mundial da Saúde (OMS), desde o início da pandemia até 01 de setembro de 2020, mais de 25 milhões de pessoas já se contaminaram e mais de 848 mil já morreram. Atualmente, as Américas lideram o número de casos, seguidas por Europa e Sudeste Asiático. Estados Unidos da América (EUA) é o país com maior número de casos e de mortes pela COVID-19, estando o Brasil em segundo lugar, tanto em número de casos quanto de mortes. Porém, quanto aos novos casos, o Brasil ultrapassou os EUA recentemente (OMS, 2020a).

Esta análise bibliométrica tem como finalidade proporcionar informações para fins epidemiológicos, para auxiliar na prevenção, no diagnóstico, no controle e em possíveis tratamentos da doença. Os dados são analisados em relação ao tempo, localização e fonte da publicação. O objetivo do presente trabalho é apresentar indicadores bibliométricos a respeito do tema "COVID-19", utilizando a base Scopus, comparando o Brasil e o mundo.

\section{REVISÃO DE LITERATURA}

\section{COVID-19}

O novo coronavírus, causador da COVID-19, é um RNA vírus, zoonótico, da família Coronaviridae, da ordem Nidovirales, e faz parte dos beta coronavírus (LIMA, 2020a). Foi oficialmente chamado de SARS-CoV-2, em 11 de fevereiro de 2020, pelo Comitê Internacional de Taxonomia de Vírus (ICTV), devido às semelhanças genéticas do novo vírus com o coronavírus responsável pelo surto de SARS em 2003 (OMS, 2020b).

Os coronavírus são vírus que possuem projeções nas suas superfícies, que lhes atribuem um aspecto de coroa à microscopia eletrônica. Exibem quatro proteínas estruturais principais: Spike (S), envelope (E), membrana (M) e nucleocapsídeo (N). A proteína Spike é a responsável pela internalização do vírus nas células através de sua interação com o receptor celular enzima conversora da angiotensina 2 (ACE2) (LIMA, 2020b).

O SARS-CoV-2 surgiu em dezembro de 2019 na cidade de Wuhan, capital da província de Hubei, na China, sendo os primeiros casos relatados relacionados ao mercado de Huanan, local onde ocorre a venda ilegal de animais silvestres. Acreditase, tendo como base estudos do genoma viral, que este não tenha sido criado em laboratório, mas, sim, seja fruto de seleção natural propiciada pelo convívio de animais selvagens de diferentes espécies, como morcegos e pangolins. Tal teoria é corroborada pela similaridade genômica entre o SARS-CoV-2 e dois tipos principais de coronavírus do morcego: bat-SLCoVZC45 e bat-SLCoVZXC21 (DUARTE, 2020).

Desde os primeiros casos do novo coronavírus notificados no mundo, os números só aumentam e, devido à velocidade e intensidade desse aumento, em 30 de janeiro de 2020, a OMS declarou uma Emergência de Saúde Pública de Importância Internacional e, em 11 de março de 2020, a COVID-19 foi declarada pela OMS como uma pandemia. Atualmente, em nível global, existem mais de 25 milhões de casos confirmados e cerca de 848 mil mortes pela COVID-19 reportadas à OMS (OMS, 2020a). No entanto, acredita-se que estes números sejam ainda maiores, dada a subnotificação de casos e atrasos nas notificações (SCHMIDT et al., 2020).

Apesar da baixa letalidade quando comparado a outros coronavírus, o SARS-CoV-2 apresenta uma alta transmissibilidade, o que se expressa pela curva ascendente do número de casos desde o primeiro registro (AQUINO et al., 2020). A transmissão desse vírus se dá, principalmente, por meio de gotículas, secreções da orofaringe e fômites, com partículas virais. Dentre os possíveis quadros clínicos, pode haver indivíduos assintomáticos ou com sintomas leves, que representam a maioria dos casos, e indivíduos com sintomas graves. Nos casos 
leves, os sintomas mais comuns são febre, tosse, mialgia, escarro, anosmia, ageusia, cefaleia, êmese, dor abdominal, diarreia, odinofagia e rinorreia. Os casos graves podem apresentar dispneia, taquipneia, dor torácica, cianose, hipotensão, sinais de esforço respiratório, linfopenia e descompensação das doenças de base (CESPEDES; SOUZA, 2020). O nível de gravidade da doença pode ser influenciado por fatores de risco e os mais conhecidos são doenças cardiovasculares e pulmonares, idade avançada e obesidade (VAZ; CASSIMIRO; SOARES, 2020; CESPEDES; SOUZA, 2020). Para o diagnóstico, deve ser realizado o exame de PCR-TR, com resultado positivo para COVID-19, ou pode haver um diagnóstico presuntivo devido à presença de um quadro clínico característico e uma epidemiologia favorável associados à tomografia computadorizada (TC), com padrão em vidro fosco periférico e bilateral dos lobos inferiores (CESPEDES; SOUZA, 2020).

A pandemia do novo coronavírus representa uma grave crise sanitária mundial que está gerando impactos sociais, econômicos e na saúde, diretamente proporcionais à sua magnitude. Devido à ausência de uma vacina para o combate à COVID-19 e ao surgimento de novos e numerosos casos com altas taxas de morbidade e mortalidade observadas, toda a população mundial começou a tomar várias medidas de prevenção, sendo a principal delas o isolamento social (PORSSE et al., 2020). Essa medida tem como objetivo diminuir a velocidade de propagação do vírus e, dessa forma, o número de infectados e de óbitos. Entretanto, junto com as medidas de isolamento social, surgiram repercussões desastrosas na sociedade, principalmente na saúde e no âmbito econômico. Foi observado que a percepção sobre o distanciamento social varia de acordo com a renda, escolaridade, idade e sexo dos indivíduos. Pessoas com um perfil socioeconômico mais elevado tiveram como maior impacto o convívio social, enquanto para pessoas com menor renda e escolaridade as questões financeiras representaram o maior problema. Aqueles indivíduos com piores condições de habitação referiram uma menor disposição a aderir à medida de isolamento social por um tempo mais prolongado (BEZERRA et al., 2020).

Além das questões econômicas, também emergiram impactos na saúde mental junto à pandemia do novo coronavírus. A população, em geral, apresentou-se fragilizada, não apenas pelas apreensões quanto à saúde física, mas também pelas questões sociais que refletem diretamente na saúde mental de todos. A mudança de rotina, junto à veiculação de notícias diariamente, pode gerar efeitos negativos na sociedade, em particular nos profissionais de saúde, tais como estresse, ansiedade e depressão (SCHMIDT et al., 2020).

Dentre todos os impactos gerados pela atual situação mundial, sendo eles diretos e indiretos, a saúde pública foi o setor mais afetado devido à sobrecarga na demanda de atendimento e leitos. Diante da pandemia, os países enfrentam um colapso no sistema de saúde, principalmente aqueles que postergaram as medidas de prevenção e isolamento social (PORSSE et al., 2020).

\section{BIBLIOMETRIA}

Bibliometria se define como estudo estatístico e quantitativo sobre a produção e difusão de conhecimento científico. Seu surgimento ocorreu no início do século, mediante a demanda que se fazia cada vez maior de analisar a produção e a comunicação científicas. Baseia-se em três pilares principais, constituídos pelas três leis: de Lotka, de Zipf e de Bradford, pesquisadores que elaboraram as leis empíricas ao comportamento da literatura, com função de, respectivamente, medir a produtividade dos autores, analisarem a distribuição e a frequência de palavras em um texto e avaliar a dispersão do conhecimento científico (ARAÚJO, 2006).

Oliveira et al. (1992apud VANTI, 2002) pregam a ideia de que o estabelecimento e acompanhamento de políticas de ensino e pesquisas devam ser norteados mediante embasamento sobre avaliação da produtividade científica.

A análise bibliométrica tem por funções, dentre outras, a avaliação das tendências e do crescimento do conhecimento, processos de citação e co-citação e a dispersão e obsolescência da literatura científica, identificação de revistas núcleo das disciplinas, mensuração do grau e padrão de colaboração entre autores, crescimento de áreas de conhecimento e surgimento de novos temas e previsão de tendências de publicação e de produtividade científica de autores, organizações e países (VANTI, 2002).

A base de dados Scopus foi criada pela Elsevier em 2004 e é uma plataforma multidisciplinar que abrange conteúdo publicado desde 1960 sobre todos os campos de pesquisa. Usada globalmente por mais de 3000 instituições de ramos acadêmicos, corporativos e governamentais, é atualizada diariamente e compõe uma das principais fontes de dados para pesquisa de informação científica interdisciplinar disponíveis (SCOPUS, 2020). 


\section{METODOLOGIA}

A coleta de dados na base Scopus, disponível no Portal Periódicos da Capes, foi realizada no dia 27 de julho de 2020, sendo usado o termo "COVID-19". Buscaram-se os artigos que contivessem estes termos no título, resumo ou palavras-chave, limitando-se a busca àqueles artigos publicados em periódicos. As expressões de busca com operadores booleanos foram:

(title-abs-key(covid-19) and (limit-to (doctype,"ar")) and (limit-to (srctype,"j"))): 14516 artigos.

(title-abs-key(covid-19) and (limit-to (doctype,"ar")) and (limit-to (srctype,"j")) and (limit-to (affilcountry,"brazil"))): 384artigos.

Obtiveram-se informações relacionadas à quantidade de artigos por autor, instituição, país, área, periódico e idioma.

\section{RESULTADOS E DISCUSSÃO}

\section{PRINCIPAIS PAÍSES}

A Figura 1 apresenta os países que mais publicaram a respeito do tema "COVID-19" na base Scopus e os países que mais publicaram sobre todos os temas.

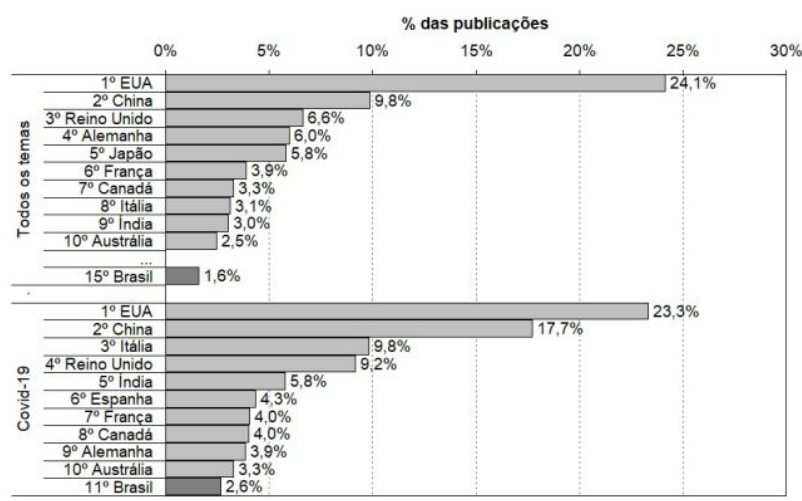

Figura 1- Países com mais publicações sobre todos os temas ou sobre o tema "COVID-19" na base Scopus. Fonte: Scopus (2020).

Dentre os países com mais publicações sobre o tema COVID-19, há certa correspondência com os países que mais publicam sobre todos os temas. No entanto, pode-se perceber que os países que foram mais acometidos pela pandemia mostraram maior envolvimento nas pesquisas sobre a doença do que costumam apresentar quando se analisa o número de publicações em todos os temas. A China se apresenta em segundo lugar nos dois parâmetros, porém sua porcentagem de contribuição aumenta de
$9,8 \%$, quanto a todos os temas, para $17,7 \%$, em relação à COVID-19. O Brasil salta da décima quinta posição para a décima primeira, quando se trata de publicações acerca da COVID-19. Países como Itália e Índia, antes em nono e décimo, respectivamente, chegam a estar entre os cinco países que mais publicaram sobre o tema. Este fenômeno pode ser atribuído a maior necessidade que esses países desenvolveram de adquirir conhecimento sobre o vírus e a doença para tentar combatê-los com maior efetividade. Contudo, os países de maior poder econômico predominam nas publicações, tanto sobre todos os temas quanto a respeito da COVID-19, o que se justifica pelo maior incentivo à ciência e educação, maior número de universidades e instituições de pesquisa, bem como maiores recursos para a realização de estudos científicos.

\section{PRINCIPAIS INSTITUIÇÕES}

Na Figura 2,podem-se observar as instituições que mais publicam sobre a COVID-19.

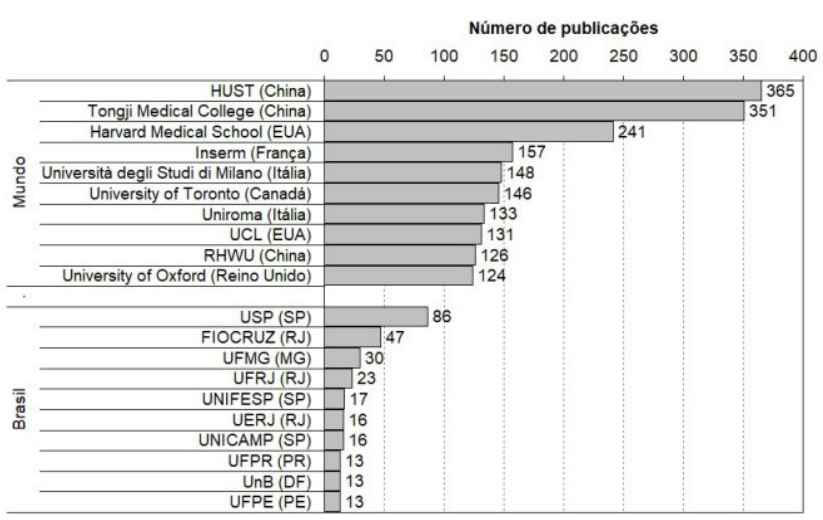

Figura 2- Instituições que mais publicam, mundialmente e no Brasil, a respeito do tema "COVID-19". Abreviaturas: HUST (HUST); Uniroma (Uniroma); RHWU (RHWU).

Fonte: Scopus (2020).

As principais instituições envolvidas nas pesquisas acerca da COVID-19 estão na China, EUA, França, Itália, Canadá e Reino Unido. Enquanto isso, no Brasil, as instituições com maior produção científica se concentram na região sudeste, com destaque para São Paulo e Rio de Janeiro, o que reforça o papel do nível socioeconômico regional na produção científica.

\section{PRINCIPAIS AUTORES}

A Figura 3 mostra os autores com maior número de publicações sobre o tema "COVID-19" no Brasil e no mundo. 


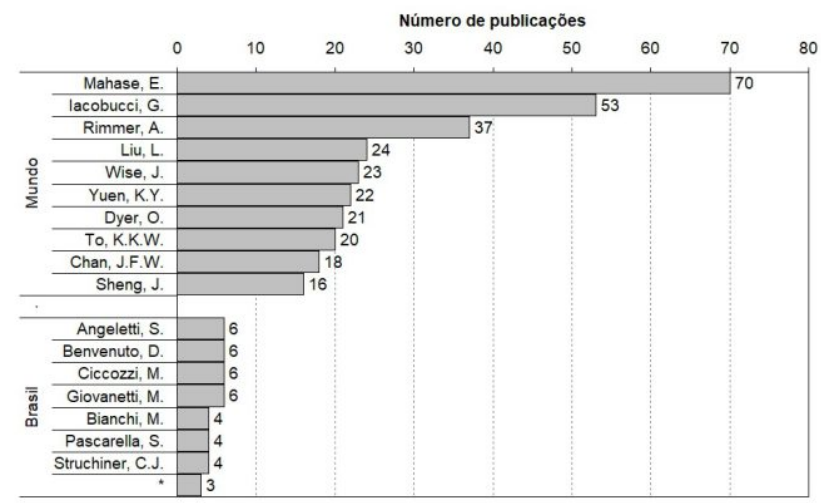

Figura 3 - Autores com maiores quantidades de publicações sobre o tema "COVID-19" na base Scopus.

Fonte: Scopus (2020).

A Mahase, E. é a principal autora, quando se trata do tema "COVID-19". Ela é filiada à revista com maior número de publicações, a British Medical Journal (BMJ). Em segundo lugar, com 53 publicações, está lacobucci, G., do Reino Unido, que possui 8 publicações no BMJ. Rimmer, A. se encontra em terceiro lugar no ranque mundial, com 37 publicações. Ele também é filiado ao BMJ.

Quanto aos autores que mais publicaram no Brasil, os principais deles publicaram 6 artigos acerca do tema "COVID-19". Todos são filiados à revista Università Campus Bio-Medicodi Roma e participaram concomitantemente como autores de pelo menos dois destes 6 artigos.

\section{PRINCIPAIS PERIÓDICOS}

A Figura 4 apresenta os periódicos com mais publicações acerca do tema "COVID-19".

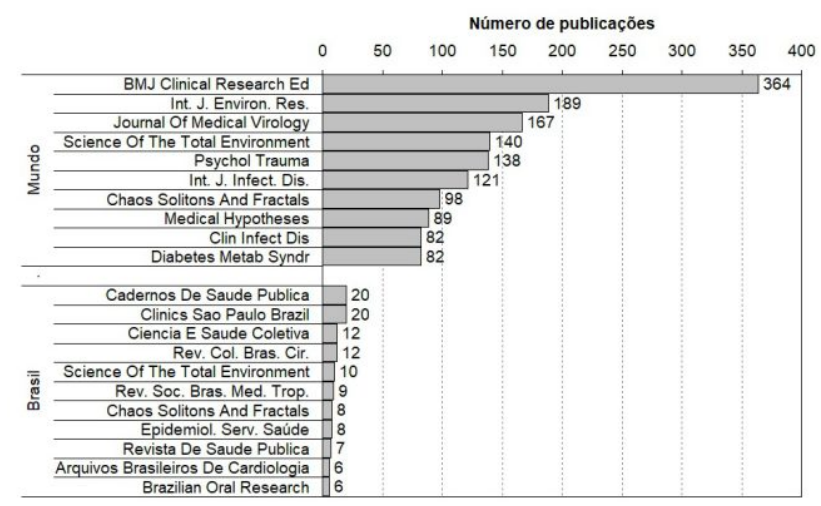

Figura 4- Periódicos com mais publicações sobre o tema "COVID$19^{\prime \prime}$.

Fonte: Scopus (2020).

Abreviaturas: Int. J. Environ. Res. (International Journal of Environmental Research and Public Health); Psychol Trauma (Psychological Trauma Theory Research Practice and Policy); Int. J. Infect. Dis. (International Journal of Infectious Diseases); Clin Infect Dis (Clinical Infectious Diseases an Official Publication of The Infectious Diseases Society of America); Diabetes MetabSyndr (Diabetes and Metabolic Syndrome Clinical Research and Reviews); Rev. Col. Bras. Cir. (Revista Do Colégio Brasileiro De Cirurgiões); Rev. Soc. Bras. Med. Trop. (Revista Da Sociedade Brasileira De Medicina Tropical); Epidemiol. Serv. Saúde (Epidemiologia E Serviços De Saúde Revista Do Sistema Único De Saúde Do Brasil).

O periódico com o maior número de publicações no mundo acerca do tema "COVID-19" é britânico e da área médica, apesar de o Reino Unido estar na quarta posição, quando se trata do ranque de países que mais publicaram sobre a COVID-19. Os periódicos com maior número de publicações no Brasil se encontram na região sudeste, nos estados de São Paulo e do Rio de Janeiro, em concordância com as principais instituições.

\section{PRINCIPAIS ÁREAS}

A Figura 5 mostra as principais áreas nas quais os artigos relacionados ao tema "COVID-19" estão vinculados.

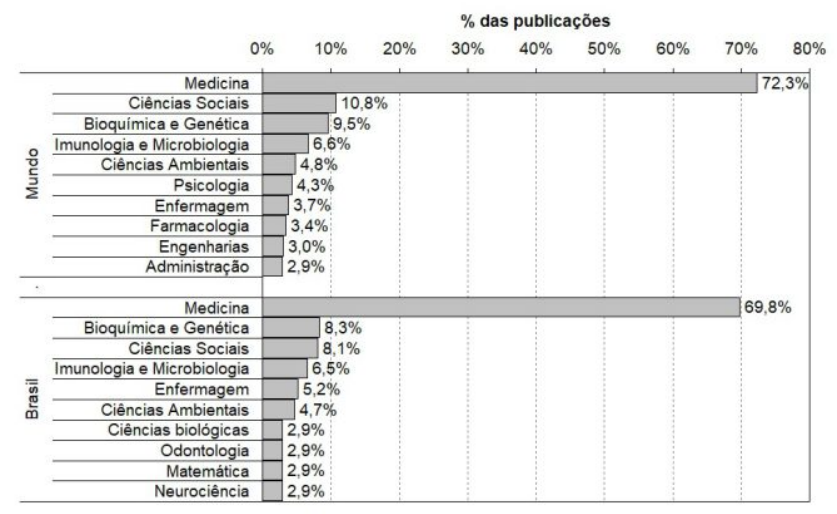

Figura 5- Principais áreas de vinculação dos artigos publicados na base Scopus e relacionados ao tema "COVID-19". Fonte: Scopus (2020).

Como esperado, por se tratar de um problema de saúde pública acima de tudo, a medicina foi a ciência com maior produção de artigos na área. Boa parte das publicações acerca da COVID-19 constitui estudos no ramo da genética, o que se justifica pela necessidade de entendimento do comportamento genético viral. $\mathrm{O}$ grande número de óbitos e infectados resulta em impactos socioeconômicos dos mais variados, que implicam 
em diversos setores da vida e da ciência, que são retratados pela representação de parcela significativa das publicações em revistas relacionadas às ciências sociais. Pode-se verificar a diversidade de impactos causados pela pandemia, de acordo com a ampla gama de áreas de atuação que desenvolveram estudos sobre o tema, que engloba não apenas a área médica e das ciências sociais, mas também psicológicas, haja vista o surgimento e agravamento de transtornos psicológicos e psicossociais decorrentes dos estresses provenientes do isolamento social e de outras alterações antes não vividas pela maioria da população, mas acarretadas pela pandemia (BORLOTI, 2020), e até das ciências exatas, como engenharias e administração.

\section{PRINCIPAIS IDIOMAS}

A Figura 6 apresenta os principais idiomas nos quais os artigos a respeito do tema "COVID-19" foram publicados.

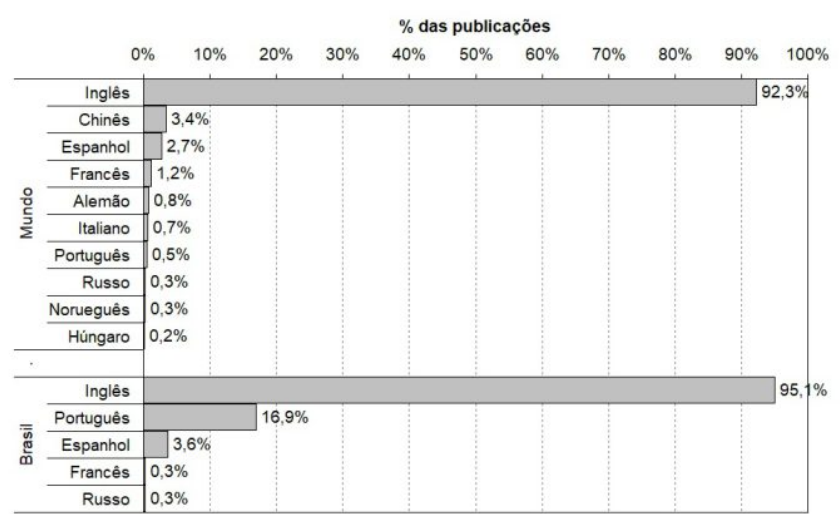

Figura 6- Principais idiomas dos artigos publicados na base Scopus e relacionados ao tema "COVID-19".

Fonte: Scopus (2020).

Como o inglês é um idioma mundial, a grande maioria das publicações foi feita nesta língua para que, assim, pudessem ser mundialmente entendidas. Os idiomas inglês, chinês e espanhol são os mais falados no mundo, corroborando para o maior número de publicação nestes idiomas acerca do tema "COVID-19". O chinês está em segundo lugar no ranque dos idiomas mais empregados nas publicações mundiais, da mesma forma que a China ocupa esta posição entre os países com mais publicações sobre todos os temas e sobre a COVID19. Apesar de a França ser o sexto país em número de publicações, o francês está em quarto lugar dentre os idiomas mais utilizados nas publicações.

Em relação às publicações feitas no Brasil, a língua mais utilizada foi a inglesa e a língua portuguesa ficou em segundo lugar, mesmo sendo a língua nativa do país. O espanhol ocupa a terceira posição, tanto das publicações mundiais quanto brasileiras.

\section{CONSIDERAÇÕES FINAIS}

De acordo com a análise dos dados, os países que mais sofreram com a pandemia e que têm mais recursos para a realização de estudos foram os que lideraram os ranques, tanto em número total de pesquisas quanto sediando as instituições que mais pesquisaram. A influência do fator socioeconômico, em nível nacional, traduz-se pela centralização da produção científica na região sudeste do Brasil, onde se reúnem as instituições com maior incentivo à pesquisa, que se concentram no estado de São Paulo e do Rio de Janeiro, assim como os periódicos com maior número de publicações acerca do tema "COVID-19" no país. Os idiomas de publicação guardam, basicamente, as proporções comuns a todos os temas.

Faz-se necessário, porém, reforçar o empenho dos países emergentes, sobretudo aqueles mais afetados pela pandemia, na produção científica a respeito do tema, a fim de ampliar os conhecimentos e nortear as ações a serem realizadas a seguir. Tal incremento pode ser realizado a partir da fomentação de pesquisa e educação nesses países, por meio de maiores investimentos nas universidades.

\section{REFERÊNCIAS}

ADHIKARI, S. P.; MENG, S.; WU, Y.; MAO, Y.; Ye, R.; WANG, Q.; SUN, C.; SYLVIA, S.; ROZELLE, S.; RAAT, H.; ZHOU, H. Epidemiology, causes, clinical manifestation and diagnosis, prevention and control of coronavirus disease (COVID-19) during the early outbreak period: a scoping review. Infect Dis Poverty, [s.I.], v. 9, n. 29, p. 1-12, mar. 2020.

ARAÚJO, C. A. Bibliometria: evolução histórica e questões atuais. Em Questão, Porto Alegre, v. 12, n. 1, p. 11-32, jan./jun. 2006.

AQUINO, E. M. L. et al. Medidas de distanciamento social no controle da pandemia de COVID-19: potenciais impactos e desafios no Brasil. Ciênc. saúde coletiva, [s.l.], v. 25, n. 1, p. 2423-2446, jun. 2020. 
BEZERRA, A. C. V.; SILVA, C. E. M.; SOARES, F. R. G.; SILVA, J. A. M. Fatores associados ao comportamento da população durante o isolamento social na pandemia de COVID-19. Ciênc. saúde coletiva, [s.l.],v. 25, n. 5, p. 2411-2421, jun. 2020. BORLOTI, E.; HAYDU, V. B.; KIENEN, N.; ZACARIN, M. R. J.Saúde mental e intervenções psicológicas durante a pandemia da Covid-19: um panorama. Revista Brasileira de Análise do Comportamento, [s.I.],v. 16, n.1, P. 21-30, 2020.

CESPEDES, M. S.; SOUZA, J. C. R. P. SARS-CoV-2: uma revisão para o clínico. Rev. Assoc. Med. Bras. [online], v.66, n.2, p.116123, 2020.

CHAHROUR, M.;ASSI, S.; BEJJANI, M.;NASRALLAH, A. A.;SALHAB, H.;FARES, M.;KHACHFE, H. H. A Bibliometric Analysis of COVID-19 Research Activity: A Call for Increased Output. Cureos,[s.l.],v. 12, n. 3, p. e7357, mar. 2020.

DUARTE, P. M. COVID-19: Origem do novo coronavírus. Brazilian Journal of Health Review, Curitiba, v. 3, n. 2, p. 3585-3590, 2020.

HOFFMANN, M.; KLEINE-WEBER, H.;SCHROEDER,S.;KRÜGER,N.;HERRLER,T.;ERICHSEN,S.; SCHIERGENS,T.

S.;HERRLER,G.;WU,N.;NITSCHE,A.;MÜLLER,M. A.;DROSTEN,C.;PÖHLMANN,S. SARS-CoV-2 Cell Entry Depends on ACE2 and TMPRSS2 and Is Blocked by a Clinically Proven Protease Inhibitor. Cell,[s.I.],v. 181, n. 16, p. 271-280.e8,Apr. 2020. doi: 10.1016/j.cell.2020.02.052

LIMA, C. M. de O. Informações sobre o novo coronavírus (COVID-19). Radiol Bras., São Paulo, v. 53, n. 2, mar./abr. 2020a. LIMA, . N. G. C. As descobertas genômicas do SARS-CoV-2 e suas implicações na pandemia de COVID-19. J. Health Biol Sci., [s.I.], v. 8, n. 1, p. 1-9, 2020 b.

MELO,M. C.;CABRAL,E. R. M.;ROLIM,A. C. A.;OlIVEIRA,R. E. M.;TAKAHASHI,F.;ARAUJO,A. C.;OLIVEIRA,G. A.;GOMES,S. D. H.;MACÊDO,R. T. D. A bibliometric analysis of global researches at COVID-19. InterAmerican Journal of Medicine and Health, [s.I.],v. 3, p. 1-4, 2020.doi: 10.31005/iajmh.v3i0.88

OMS - ORGANIZAÇÃO MUNDIAL DA SAÚDE. Coronavirus disease (COVID-19) pandemic. 2020a. Disponível em: https://www.who.int/emergencies/diseases/novel-coronavirus-2019. Acesso em: 10 jul. 2020.

OMS - ORGANIZAÇÃO MUNDIAL DA SAÚDE. Naming the coronavirus disease (COVID-19) and the virus that causes it. 2020b.Disponível em:

https://www.who.int/emergencies/diseases/novel-coronavirus-2019/technical-guidance/naming-the-coronavirus-disease(covid-2019)-and-the-virus-that-causes-it. Acesso em: 10 jul. 2020.

PORSSE, A. A.; SOUZA, K. B. de; CARVALHO, T. S.; VALE, V. de A. Impactos Econômicos da COVID-19 no Brasil. Nota Técnica NEDUR-UFPR 01-2020, Núcleo de Estudos em Desenvolvimento Urbano e Regional (NEDUR) da Universidade Federal do Paraná, Curitiba, abr. 2020.

SCHMIDT, B.; CREPALDI, M. A.; BOLZE, S. D. A.; NEIVA-SILVA, L.;DEMENECH, L. M.Impactos na Saúde Mental e Intervenções Psicológicas Diante da Pandemia do Novo Coronavírus (COVID-19). Estud. psicol., Campinas, v.37, p. 1-13, maio 2020. SCOPUS: access and use Support Center. Elsevier, 2020. Disponível em: https://service.elsevier.com/app/answers/detail/a_id/15100/supporthub/scopus/. Acesso em: 10 jul. 2020.

VANTI, N. A. P. Da bibliometria à webometria: uma exploração conceitual dos mecanismos utilizados para medir o registro da informação e a difusão do conhecimento. Ci. Inf., Brasília, v.31, n.2, maio/ago. 2002.

VAZ, I. C. O. G.; CASSIMIRO, R. D.; SOARES, V. Influência de doenças cardiovasculares e obesidade no quadro clínico de pacientes com a Covid-19.In:MOSTRA ACADÊMICA DO CURSO DE FISIOTERAPIA, 8., 2020. Anais [...] UniEVANGÉLICA, 2020. YANG, W.; CAO, Q.; QIN, Le; WANG, X.; CHENG, Z.; PAN, A.; DAI, J.; SUN, Q.; ZHAO, F.; QU, J.; YAN, F. Clinical characteristics and imaging manifestations of the 2019 novel coronavirus disease (COVID-19):A multi-center study in Wenzhou city, Zhejiang, China. Journal of Infection,[s.I.],v. 80, p. 388-393, 2020. 